\title{
6 Take a ride into the danger zone?
}

\author{
Assessing path dependency and the \\ possibilities for instituting change at \\ two Swedish government agencies
}

\author{
Benedict E. Singleton and Gunnhildur Lily \\ Magnusdottir
}

\section{Introduction - The need for institutional change}

With the exception of the community of climate change deniers, there is largely consensus that global human society needs to go through a variety of changes in order to ensure continued sustainability. The UN's sustainable development goals (SDGs) emphasise the urgency of these changes and provide an incentive to recognise the importance of social differences, including gender differences, in climate politics (see also Morrow, this volume). Furthermore, the necessary societal changes needed for a successful climate transition call for deeper understanding of the complex social, economic and environmental effects of any climate action on different social groups, defined by intersectional climate-relevant factors such as gender, age, class, education and location. This means that the societal changes needed for sustainable climate politics will have diverse, disparate effects within the population (Magnusdottir and Kronsell; Bipasha, this volume). Gender, nested with other intersecting social differences, has been shown to be of relevance for consequences of climate action (Alston and Whittenbury, 2013; Magnusdottir and Kronsell, 2015, 2016; Nagel, 2012; Resurrección, 2013). As such, how to transition to sustainable societies is a topic of considerable scientific debate as is the discussion of the importance of social justice in climate transition. Whilst 'Green Radicals' may argue for substantive, wholesale changes to the underpinnings of contemporary economies and societies, still 'environmental problem-solvers' argue for a more pragmatic stance, i.e. reorientation rather than revolution (Dryzek, 2013). In this context, we argue that it is important to explore the role and possibilities that climate institutions and the civil servants embedded in them can play in orienting society in a more sustainable and socially just direction. This chapter examines the possibilities for action among civil servants within two Swedish climate institutions, with a specific focus on their potential to recognise and work with climate-relevant social differences, such as gender, age, location and class, in their policy-making. The climate institutions in question are two government agencies: the Swedish Environmental Protection Agency (Naturvairdsverket, SEPA) and the Swedish Transport Administration (Trafikverket, STA). Based on interviews with agency staff, we draw on feminist

DOI: $10.4324 / 9781003052821-6$ 
institutional theory to examine the extent that respondents consider themselves bound by the path dependency of their institution and the extent to which they report potential action towards change. The purpose of this analysis is to highlight the potential ways that agency staff may be empowered to make use of a feminist or intersectional understanding of social differences in order to develop socially inclusive and just climate policy and potentially overcome institutional path dependency.

To be successful, climate transition strategies need to acknowledge social differences and thus consider the needs of different social groups. Otherwise, they not only risk being deemed undemocratic but also ineffective in their attempts to drive forward the large-scale societal changes needed for climate transitions (Laestadius, 2018). Our intention is to contribute by signalling the steps climate institutions could take in order to achieve their transformational potential (cf. Eckersley, 2020).

The chapter is structured as follows. In the next section, we discuss our guiding theoretical tool - feminist institutionalism - and its relevance to our case, e.g. how a 'gendered logic of appropriateness' might prevent the full inclusion of gender into climate policy-making. We then discuss the cases in question and the material and methods employed. Thereafter, we analyse the collected data, with the help of feminist institutionalism, highlighting how respondents framed their activities in terms of following a top-down and historical trajectory, while at other times they would describe how they are able to act on their own initiative. We conclude by suggesting that efforts to orient Swedish Government agencies towards a just climate policy require tools designed both to 'convert' senior staff to adopt the approach and to demonstrate civil servant initiatives fall within the agencies' legitimate purview.

\section{Following a well-beaten path: institutional changes, path dependency and the 'stickiness' of institutions}

We make use of institutional literature, especially including feminist institutionalism in our analysis. We are inspired by intersectionality literature on climate change (Kaijser and Kronsell, 2014) and we expand the traditional gender lens of feminist institutionalism to include climate-relevant social factors, such as education, class, age and geography, which intersect with gender (see further in Magnusdottir and Kronsell, in this volume).

Institutionalist approaches study institutions. Separate strands of institutionalism define institutions differently and we define them broadly, including both formal and informal climate authorities. Thus, our definition of 'climate institutions' also includes: 'rules, norms and practices embedded in historical traditions and legacies, giving some stability and predictability to political and public life' (Hysing and Olsson, 2018, p. 9; cf. March and Olsen, 1996; Mackay et al., 2010). Put another way, as social beings, humans coproduce understanding of the world with institutions through which they live and act (Douglas, 1987). People perform social relationships concomitantly with narratives of the world, which 
together comprise institutional patterns (Thompson, 2008). As social organisations, what people embedded in institutions

assume to be true shapes what they value. This shaping occurs through the processes of proactive manifestation through which assumptions provide expectations that influence perceptions, thoughts, and feelings about the world and the organization. These perceptions, thoughts, and feelings are then experienced as reflecting the world and the organization. Members recognize among these reflections, aspects they both like and dislike, and on this basis they become conscious of their values (without necessarily being conscious of the basic assumptions on which their experiences and values are based).

(Hatch, 1993, p. 662)

A key concern of institutional theorising is how institutions change. In this, it echoes wider social scientific discussions about the relationship between social structures and individual agency or power (Mahoney and Thelen, 2009). Within feminist institutionalism, institutional practices are understood to be based on a logic that may make the inclusion of gender appear less appropriate and less desirable. This builds on March and Olsen's (1996, pp. 21-38, p. 161) new institutionalist ideas about how institutions are reproduced through patterns of action in a 'logic of appropriateness'. In the context of this chapter, this might, for example, mean that dominant economic and technical solutions to societal problems are 'sticky' or deemed more appropriate than solutions focusing on climaterelevant social differences such as gender. The fact that Swedish environmental politics have historically been framed in the context of 'ecological modernization' (Lundqvist, 2004), which prioritises economy over social concerns might lead to path dependency in Swedish climate institutions and limit the scope for inside activism. Thus, economic solutions might be reproduced and normalised within institutions, limiting space for innovation and civil servant activism. Put differently, individual policy-makers are assumed to follow embedded rules and routines, according to what is appropriate for their social and professional role and individual identity. What is considered appropriate in any given situation is not trivial. 'Actions are fitted to situations by their appropriateness within a conception of identity' (March and Olsen, 1996, p. 38).

'Well-established institutions are even taken for granted and tend to produce path-dependent action' (Hysing and Olsson, 2018, p. 9). What this means is that those embedded in institutions act based on past institutional actions, with positive feedback from successful earlier actions encouraging the development of a particular institutional 'path' or 'mission trajectory' (Goodsell, 2006). Put another way, an institutional worldview represents a paradigm within which particular actions are encouraged or constrained, providing a framing of how the world should be. They may also function to retroactively maintain or alter existing assumptions (Hatch, 1993, p. 664). In this chapter, we are interested in the extent that respondents frame their actions around socially just climate 
transition with reference to the institutions within which they are embedded (the government agencies).

Path dependency may potentially be challenged by actions in the wider world; however, endogenous change is also possible. Not all institutions proceed along a static trajectory until an external crisis precipitates change. Institutional theorists have highlighted that those within institutions, including civil servants, do not necessarily agree with an institution's worldview and are able to work overtly or covertly to engender institutional change (cf. Johnsson-Latham and Kronsell in this volume). As such, civil servants can be 'inside activists' seeking to further their values within an institution or, in contrast, toe the institutional line (Hysing and Olsson, 2018). Governing authorities are of particular interest, as the officials within them necessarily require adaptation and discretionary power to carry out their role in dynamic situations where official direction may be vague and/or conflicting (Applbaum, 1992). However, concomitant to this discretionary power is the need for a certain legitimacy. If this is lost then public confidence in government may be undermined (Hysing and Olsson, 2018, p. 141). Linked to this, as the rise of Trump in the US illustrates, politicians may make political capital by depicting public officials as part of a 'deep state' opposed to what they consider the will of the people. As such, public officials walk a fine line and become involved in various societal conflicts through the actions they take. This highlights two dimensions relevant to institutional change. Firstly, institutions must be mindful of their social legitimacy - their standing within broader society affects their actions (Hatch, 2018). Secondly, and linked to the first point, institutional worldviews will contain assumptions about their place and role in society. Both of these usually entail a certain path dependency as agencies are steered by their own and outsiders' ideas about what they can and should do.

At the individual level, civil servants do make decisions and periodically can act against dominant institutional structures, which suggests individual agency and room for 'inside activism' (Chapter 5, this volume). This is one of the ways that institutions change. Within dynamic contexts, actors and structure thus hang together within processes of structuration (Giddens, 1984). As such, there are times when actors embedded in institutions display path dependency whereas at others, they are able to act with limited reference to the organisation (Hysing and Olsson, 2018).

\section{Identities and role expectations}

Feminist institutionalism has almost exclusively focused on gender, but we suggest, as already stated, that the intersectional understanding of identities and social factors other than gender is needed for our analysis. This means that we expand the gender lens of feminist institutionalism to include factors such as education, class, age and geography, when exploring both the role of professional identities of policy-makers and their understanding of climate-relevant social differences.

Professional identities in climate institutions are important to study since climate actions and policies are not only the product of path-dependent, sticky 
institutions but also determined by how individual policy-makers make sense of their position and professional identities. Feminist institutionalism argues that institutions organise power inequalities in two main ways. Firstly, through formal as well as informal rules and practices. Secondly, through co-production of identities intertwined with the daily life and logic of institutions. In most Western states, including Sweden, climate policy-making primarily takes place in the energy, environment or transport sectors. As such, the norms and path dependencies expressed in the rules and culture of the institutions active in that sector will affect understandings of how social power relations work within policymaking. In addition, the professional identity of the policy-makers, perhaps educated as engineers or economists, might make technical and economic solutions seem most appropriate. In our analysis, we side with Arora-Jonsson and Sijapati (2018) and propose that professional identities of civil servants and institutions are of considerable significance when studying climate institutions. As outlined above, climate policy has been criticised for being overly reliant on technical and economic action instead of also acknowledging the social dimension of climate change. Further recognition of the social dimension of climate change would, for instance, mean that climate-relevant differences in behaviour, adaptation, views and vulnerability of different social groups are taken into further consideration in climate policy-making. This limited recognition of social difference arguably limits the possibilities for institutional action, with consequences for the possibility of just sustainable climate transitions.

Of particular relevance to this chapter is the notion of 'green inside activism' (Hysing and Olsson, 2018), not dissimilar to the notion of femocrat or gender activist, referred to in other chapters in this volume. Inside activists are individuals 'engaged in civil society networks and organizations, who hold a formal position within public administration, and who act strategically from inside public administration to change government policy and action in line with a personal value commitment' (Olsson and Hysing, 2012, p. 258). In our study, we look for such inside activism in terms of how these civil servants describe their possibilities for initiating climate acts - e.g. critical acts built on an intersectional or gendered understanding of climate change.

\section{Cases and methods}

We collected the data for this chapter through an interview study in the spring of 2020, of civil servants in Swedish climate institutions, and based it upon the responses of two government agencies, the Swedish Environmental Protection Agency (EPA) and the Swedish Transport Administration (STA). We briefly present these agencies in turn. The Swedish governmental system is characterised by relatively small government ministries (headed by elected politicians) and relatively large and rather autonomous government agencies (myndigheter, staffed by public officials). Agencies fall under the direction of the government, but have a certain amount of their own influence, dealing with actors at all social scales. Agencies typically have a sector of responsibility, within which they 
are influential. In their work, agencies provide evidence for policy, act to realise government policy and respond to Swedish and international climate goals (e.g. Agenda 2030) (Swedish Government, 2017). Notable to Swedish climate policy is the absence of a specific climate agency. Instead, climate action is dispersed within different agencies as considered relevant. This structure is similar to how climate politics are organised in many other European states, including other Nordic states with the exception of Norway (Magnusdottir and Kronsell, 2015), the EU (Chapter 3, this volume) and the German Federal Government (Chapter 5, this volume). However, governmental agencies in Sweden might be considered more autonomous in their decision-making than many of their European counterparts.

The Swedish Environmental Protection Agency is the state agency for environmental issues, employing around 600 people across two offices in Stockholm and Östersund (Oscarsson, 2020). It supports Swedish governmental action plans every four years alongside other activities (Persson et al., 2019). This includes (but is not limited to) monitoring Sweden's environment in terms of pollutants, invasive species and so forth, and collating knowledge. It also carries out work maintaining Sweden's network of nature reserves. The SEPA also develops and implements environmental policy, cooperating with other agencies. The SEPA was selected for this research project due to it's heavy involvement in climate activities across the board. In contrast, the Swedish Transport Administration, (STA) is responsible for long-term transport infrastructure planning, construction and maintenance, and as such works with climate policies in relation to transport. Transport is one of the heaviest contributing sectors to Swedish carbon emissions, rendering the STA relevant to this project (Naturvårdsverket, 2012). The STA is an extremely large agency, with around 9000 employees. Based in Borlänge it has regional offices in six other Swedish cities (Trafikverket, 2019).

Initially, we selected respondents purposively, with individuals at each selected agency previously signalling their interest in participating in this study. We then selected further respondents utilising snowball sampling. We continued to seek out new respondents until we reached a saturation point, with the same people repeatedly suggested to us (Bryman, 2004). In total, we conducted nine interviews with SEPA staff (iEPA01-09, four women and five men) and six from the STA (iSTA01-06, two women and four men). Respondents held different levels of seniority within their respective organisations. SEPA respondents held various relevant roles, such as investigators and analysts around carbon emissions, as well as policy advisors. STA respondents included investigators, project managers and goal directors. Because of the ongoing Covid-19 crisis, we conducted all interviews online using Zoom or Skype for Business software. Having acquired informed verbal consent, we recorded each interview. We organised each interview in a semi-structured manner around a research guide. Questions focused upon a) respondent background and experience; b) interpretations of social justice within each agency; and c) the institutional contexts within which agencies operate. Following the recordings, we transcribed each interview and utilised ATLAS 8 qualitative analysis software to interrogate the data. The interviews 


\section{Singleton and Magnusdottir}

were originally conducted in Swedish, but we have translated the extracts utilised here.

Several writers have tried to theorise the links between institutional worldview and institutional activity and change (cf. Hatch, 2018). For example, Hatch (1993) describes a dynamic system where assumptions and values of the world manifest in cultural symbols and artefacts. This research does not directly utilise such a framing but shares with it the basic ontological standpoint that respondents' interview discourses are reflective of their organisational cultures, coproduced with their institutional worldviews. We, thus, pay attention to the assumptions and values evidenced by respondents.

\section{Top to bottom, bottom to top? Change possibilities at the SEPA and STA}

Respondents from both the SEPA and STA made various statements about their ability to change their agencies' emphases around climate change action and social justice. The picture painted was, at times, seemingly contradictory. Respondents would frame dominant approaches towards climate and social justice as dependent on instructions laid down elsewhere, predominantly from the government. However, at other times, respondents would also assert that they had space for individual and institution-instituted action. The following paragraphs discuss this dissonance. We then turn to the implications this picture presents for efforts to overcome institutional path dependency and incorporate social justice into the SEPA and STA's climate change action.

When questioned on the possibilities for incorporating broader conceptualisations of social justice in their climate change work many respondents asserted that a key factor was their agencies' remit and the tasks (uppdrag) that they received from the government. Respondents would characterise the historical trajectory of their agencies' involvement with climate change work as a product of Swedish governmental decisions. This could be in the form of direct assignments of tasks, or it could be through the governments' undertakings regarding international agreements (such as Agenda 2030) and climate targets, which may express social sustainability goals:

Either you get your assignments via the instruction [Swedish government rules about each agencies remit], or you get it every year when you receive a regulation letter [from the government] or you get different types of government assignments during the year. ... We get [assignments] not only from the Ministry of the Environment, but we get it from ... the Ministry of Finance or... [The orders] That we together with other authorities should do things.

(iEPA04)

We have taken Agenda 2030 to our hearts ... It was a government assignment that was about what can [STA] do to achieve Agenda 2030? We have 
interpreted this as partly what should the transport system do. We call it Target 2030, ten aspects and fourteen goals.... we call it which piece of the cake we should make, what is it that the Swedish Transport Administration can contribute to, for example, achieving the climate goal or traffic safety, or accessibility throughout the country or accessibility for everyone ... [the] more social sustainability goals.

This also meant that respondents voiced an unwillingness to act on things that they perceived as outside of the agencies' purview. This presented a particular challenge when it came to issues such as social justice that cut across multiple actors' jurisdictions within the Swedish governance system.

The Swedish Transport Administration is not allowed to work to influence behaviour, so this means that [social justice] requires close cooperation with other actors, such as municipalities. So that it is they who, as it were, are allowed to carry out these first steps to influence behaviour .... yes, talking about norms and values and so on. It is not a mission we have.

(iSTA01)

Personally, I try to achieve a transparent basis for decision-making. We are not politicians, we are not decision-makers, we are civil servants, so we must, as it were, show politics what the consequences will be of their decisions.

This also meant that when social justice did come in the fact that it was neither agency's main focus meant that it was dealt with in an ad hoc fashion. Thus, for example, some SEPA respondents described social justice as more of an add-on to their broader environmental role.

We do some analysis; we look at distributional effects as far as possible ... Most recently, I looked at tax deductions for work journeys, looked at how it affected different geographical areas. However, I must say that it is something that we need to develop, we discuss it a lot: how we should incorporate additional distributional effects into our analysis ... We look primarily at the emissions effect.

(iSEPA02, our emphasis)

Repeatedly, respondents would thus paint a picture of top-down decision-making directing their activities. A distinct normative assumption emerged that agencies work under the government, and concomitantly values around maintaining this relationship were in evidence (which is expanded on later).

However, it would be inaccurate to state that agency staff do not have a role in shaping and carrying out policy (Svara, 2001). At certain other times, respondents from both the SEPA and the STA would also indicate that they had 


\section{Singleton and Magnusdottir}

a certain amount of innovative freedom. This would involve the formation of internal networks to discuss issues beyond the official remit as well as anticipating the agencies' future roles.

But the government has never really had to tell us directly ... 'we want you to make [climate-based] demands in your procurement'. Without it, we have ourselves [made the decision]. However, [the government] was very interested when they saw that we started making such demands. But they have never said anything about 'you should not do that, or you should do that'.

(iSTA02)

But we also do some self-initiated analysis where we try to be a little proactive and see what the things are that we will need to work on in the future. And do not just sit and wait for the assignments to come. Because they can have a fairly short response time, and then it is good that you have done as much analysis of the problem as possible.

(iEPA07)

Furthermore, while the agencies' roles include responding to requests for information from the government, they also had a role in screening what information the government receives from them. Thus, respondents also described making judgements about the amount and nature of information policy-makers need as well as consideration about what issues they need to raise to prominence. Respondents, thus, highlighted that agency staff had a certain discretion in their action (Applbaum, 1992).

What we do is that we work with regard to our taskmaster, the government, and then give them the analysis that they need to have, or what we judge they need doing.

(iSEPA02, our emphasis)

But then I think this pressure to work with social sustainability now, it probably comes both from above and below, I think. A bit like the environmental issue has been, that there are also interested people, it is enthusiasts in the organisation who think it is important.

(iSTA05, our emphasis)

Likewise, this involved some awareness of the way broader political winds were blowing, and at times respondents voiced an unwillingness to becoming embroiled in broader left-wing/right-wing politics. In these cases, issues of social justice and indeed, environmental issues, were framed as part of left-wing politics. However, this implied tying the hands of the agency staff. As employees of expert-driven, theoretically non-political agencies, such questions were not theirs to discuss. There was also a further element to this; respondents admitted that agency workers could and would try to anticipate future information gaps 
and needs in their work. So, for example, one respondent described the SEPA preparing for future information requirements around European climate action by starting analysis early, before requests for information started coming in. This is suggestive of institutional values encouraging creativity rather than simply rote bureaucratic obeisance to established routines.

Such behaviour speaks of the potential of agency staff to be 'inside activists' in the sense that they can overtly and covertly act to further their own political agendas to a certain extent, independent of the directions of their taskmasters (cf. Hysing and Olsson, 2018). However, in this ability to make judgements and act independently of government direction, respondents were also open and reflexive about their own limitations in this regard. Respondents described how their own professional and academic backgrounds played an important role in their approach to their work and the need to incorporate social justice issues. Thus, this contributed to a tendency to follow extant ways of doing things.

When I started there in the 00s, you already have a form of ... policy instruments ... in place. And we have that as a starting point when we write our report, we describe that we have a carbon dioxide tax in Sweden, because we already had that then. ... So, it is probably some form of path dependency, that we already from the beginning have ... certain instruments in place.

(iEPA05)

Several respondents characterised agency employees as often coming from natural scientific, economic, or engineering backgrounds and this affected how they understood their role, which is in line with the institutional literature (AroraJonsson and Sijapati, 2018, Hysinge, 2018). Thus, an agency's own backgrounds and interpersonal networks would affect how they approached particular issues or assignments.

I think there are many at the Swedish Transport Administration who are engineers and thus, the culture is like engineering culture. We probably have many other professions as well, but the culture is engineering culture. Then you want to measure, you want it a little simple, you want little neat tables.

(iSTA04)

There are still large parts of the Swedish Transport Administration who believe very much in technological development as the solution to the climate issue, for example. Little boys' toys, like this [laughs].

The question of 'activist behaviour' within government agencies was, to a certain extent, considered ambivalently. When queried on their action, respondents would voice a respect for their role following the government's direction. Indeed, 
one respondent in particular articulated that there were risks to agency workers following their own personal passions rather than doing their job.

[T] he most common disease is civil servant activism. That you want so much with your own agenda so that you push something very hard yourself, more than what you actually have a mandate for, either from a political or civic point of view. And to be honest, it is actually very common in the environmental field, and that's probably because it is so important.

The same respondent asserted that different agencies seemed to have different organisational cultures in this regard, with some agencies' staff being in the respondent's eyes 'too activist', which brings with it the risks that they base their work solely upon their own experiences/preconceptions, rather than decisions in a rational manner upon a scientific basis. One of the stated risks of such an approach was losing touch with the reality of policy effects upon people's lives, in turn causing iniquities and/or fomenting public resistance (iSTA06). This echoes concerns of unchecked civil servant activism making their actions more manipulative than simply facilitating the smooth running of Sweden's systems (Bellone and Goerl, 1992; Irvin and Stansbury, 2004). Thus, while a certain independence was valued, this was also shackled by concerns about the legitimacy of agency action and its relationship to democracy.

This combination of top-down and bottom-up governance had direct implications for respondents' views on the possibility of organisational change. Thus, when asked to consider ways of incorporating the understanding of intersectionality as a way to develop socially just climate policies, the respondents repeatedly asserted that change should come from above, either in the form of government direction, or from senior agency staff. At the same time, respondents' were also interested to learn more about an intersectionality approach in climate policymaking and expressed a preference for concrete examples having direct relevance for their work. Indeed, several respondents felt that there was a need to find ways to better incorporate social justice into their agencies' climate work.

\section{Discussion: implications for institutional change}

These data suggest an immediate first interpretation, in the case of the SEPA and STA, that institutional change is dependent on top-down guidance from the Swedish Government. Respondents framed institutional values around the legitimacy of government direction and their limitations in acting independently. Whilst this top-down view of agency work is the formal framework for Swedish state agencies, it misses the undoubted action possibilities that government agencies have. The study also found that agency staff take an active position in interpreting their role and guiding the government by making judgements about what information the government needs and anticipating future work and research directions. Values around creativity and expert-based predictions of future needs 
were thus extant. Agency staff were seen to have the potential to push particular issues that they themselves were passionate about, highlighting the possibility for 'inside activism' (Hysing and Olsson, 2018). However, in this, staff are also constrained by the particular historical trajectories of the institutions that enfold them (cf. Hatch, 1993) and the extent that they may exercise discretion in their professional roles is a long-standing debate (Applbaum, 1992). These constraints, or alternatively, the agencies' institutional path dependency might make the inclusion of gender and other social factors appear less desirable or appropriate and thereby limit the room for inside activism (Mackay et al., 2010; Magnusdottir and Kronsell, this volume).

Agencies very seldom attempt to address problems in completely novel fashions; past experiences affect both interpretation of their various assignments by agency staff, as well as the way they innovate and institute institutional change (or not). As such, path dependency was evident on a number of levels. Firstly, the tendency to follow previous practice directly affected the types of information that agencies accessed and utilised in their work. In the Swedish context, where climate policy-making primarily takes place in the energy, environment, or transport agencies, the norms and path dependencies expressed in the rules and culture of those institutions might make technical and economic solutions seem most appropriate and, thereby, information and knowledge about the relevance of gender and other climate-relevant social factors might be excluded. Secondly, the institutional frames employed had a normative feature - how respondents framed Swedish society affected how they approached different tasks (cf. Singleton et al., forthcoming). Thus, path dependency is influential even in situations where respondents are able to take action towards institutional change. Put differently, respondents mentioned that, at times, it was hard to know what they missed because their epistemological positions were informed by their institutional embeddedness and experience.

All this has direct implications on any efforts to inculcate change. This section discusses these implications with particular reference to Swedish agencies as institutions. Particularly, we focus on what we have established as a particular identity that many respondents framed in their interviews. We call this their identities as civil servants (ämbetsmänniskor) that they perform (or aspire to perform) in their work roles. To varying degrees, many respondents framed an ideal that civil servants should be neutral in their work and this limited the extent to which they should be 'activists' for social justice within their climate activities. At times, they evidenced a certain pride in this role (cf. Olsen, 2006). Throughout the interviews, there was a distinct preoccupation with the legitimacy of respondents in their role as civil servants, which one could also interpret as the logic of appropriateness of the role. While the institutions that civil servants find themselves in are not totally and completely controlling (cf. Goffman, 1961), they do affect how those embedded in them go about action. For example, iSTA06 argued, in effect, that too much discretionary activism would push agencies into a danger zone with civil servant acting illegitimately. These institutions can likely affect several of the dilemmas that may arise for them in their work, for 
example how 'radical' they can be - for instance, do the institutional norms allow a gendered or an intersectional approach in their work? Or how much action they can take without explicit direction/collective agreement and how open any activist activities can be (Lowi, 1993; cf. Hysing and Olsson, 2018, pp. 110-114). Respondents articulated norms of agencies as apolitical units, seeing their legitimacy in part as linked to their separation from 'politics' (Svara, 2001; cf. Olsen, 2006). Fortunately, the literature on public administration suggests several ways in which civil servants may take legitimate action. These, combined with the data, provide potential avenues for engendering institutional change without endangering the social legitimacy of government agencies (cf. Hatch, 2018). It should, however, be noted that these suggestions are rooted in the collected data, which constitute respondents' representations of their agencies. As such, more in-depth (ideally field-based) work is required for more precise, targeted suggestions (e.g. along the lines of Hatch, 1993).

The first, and most obvious, strategy for institutional change suggested by the data is to enlist allies further up in the hierarchies of the agencies, in the form of politicians or senior agency figures. Legitimacy could thus be garnered by involving those with democratic legitimacy (Hysing and Olsson, 2018, p. 150). Respondents expressed a desire for clear direction on the integration of social justice in their climate change work. Practically, however, this may prove challenging and indeed, the idea of a neat separation of politicians and bureaucracy (i.e. change is simply a matter of top-down direction) is an inaccurate portrayal of the interwoven reality (Svara, 2001, 2006). Nevertheless, limited recognition of social justice or climate-relevant social differences could be perceived as a matter of a democratic deficit, potentially affecting the legitimacy of institutions.

Secondly, on a simpler level, respondents' views on integrating social justice into climate work stress the importance of following the direction of politicians. In effect, legitimacy in their eyes links to following the decisions of those with a democratic mandate. A first simple step, then, is to highlight how desired institutional change - rather than embodying revolutionary action - actually involves following the direction of the agencies' political masters. For example, in the case of our ongoing research on Swedish climate institutions, ${ }^{1}$ we will seek to frame an intersectionality approach as following government policy, rather than agency activism. Going forward, we will highlight how intersectionality has direct relevance to Sweden's climate obligations (for example, Agenda 2030), in turn directly related to social justice issues and concepts (Swedish Government, 2017). Legitimacy is thus conferred by highlighting how apparent change conforms to established rules and norms of sticky institutions (March and Olsen, 1996; Beetham, 2013, p. 15). By establishing that change is evolutionary within an agency's legitimate 'mission trajectory', respondents' concerns that they are acting out of turn will be ameliorated by illustrating that it falls within established rules and norms (Goodsell, 2006). The feminist institutionalist literature, however, points out that institutions organise power inequalities through their formal as well as informal rules and practices. This might mean that efforts to institute 'legitimate' institutional change based on established norms and rules 
only reinforce social power inequalities, excluding new intersectional knowledge. Linked to the second point, one can also make appeals to arguments about how agencies taking action may be legitimate. Margaret Stout (2013) has identified three ways that bureaucratic actions may be shown to be legitimate. These are by '(a) decentralising authority and responsibility to the people; (b) defining public interest in relation to specific situations in dialogue with affected stakeholders; and (c) engaging in processes in which citizens can actively hold officials accountable' (quoted in Hysing and Olsson, 2018, p. 155). As such, where appropriate, one can make arguments that a change will improve the institutional accountability and thus add legitimacy. Accountability has four dimensions 'Transparency, liability, controllability, responsibility and responsiveness' (Koppell, 2005, p. 94). Based on our intersectional and feminist institutionalist starting points, we can argue that greater nuance in framing Swedish society will allow for greater representation and acknowledgement of marginalised groups in agency work and thus improve institutional legitimacy (cf. Hysing and Lundberg, 2016). Public administrations also gain legitimacy through their roles as collators and providers of expert knowledge for government use (Goodsell, 2006, p. 630). As such, we can argue that by integrating intersectional understanding into their work, respondents will be developing needed-expertise and, thus, gain greater legitimacy as the experts on the various sectors of Swedish society. Along similar lines, we will also point to research highlighting the robust support within the Swedish population for multiculturalism, for example (Ahmadi et al., 2016). We can thus stress the democratic legitimacy for seeking broader framings of Swedish society.

\section{Conclusion}

In this chapter, we have presented data and analysis drawn from interviews with staff at the Swedish Environmental Protection and the Swedish Traffic Administrations. As a part of our research project seeking to find ways to integrate intersectional insight into agency work on climate change, we were interested in how institutional path dependency manifests in respondents' representations of their roles. Our findings reveal that, in varying degrees, respondents agreed that their possibilities for action were limited both in a top-down manner by the directions of the Swedish Government and by sticky norms and values within their organisations. There was also strong emphasis on values of democracy, accountability and legitimacy, which according to many of the civil servants limited their room for potentially critical action leading to further recognition of social differences. This is interesting since one may interpret the limited representation of different social groups in climate policy-making, as well as lack of understanding about the intersectional nature of climate effects, as a form of democratic deficit. However, at the same time, many respondents also revealed that agency staff had certain discretionary powers to influence both research and policy and, at times, could play a steering role for governments by making decisions about the information policy-makers receive. In this description, respondents, thus, spoke 
positively around creativity and problem-solving. Both of these sets of values embody a certain path dependency. In the former, external prescriptions regarding agency roles set the path on which the institutional worldviews develop; in the case of the latter, staff drew upon their professional and academic backgrounds, favouring the types of initiatives and the policy research and implementation tools they were receptive to and used. This contradictory picture leads to suggestions about how to develop a more just and sustainable climate policy in a path-dependent institutional environment, which still allows for some critical initiatives. These are: firstly, gathering and including various types of knowledge and information on climate-relevant social factors early in the policy-making process. Secondly, increasing civil servants' awareness, with the help of feminist institutionalism, about challenges in institutional environment. Thirdly, enlisting high-level allies (top-down governance) to encourage particular directions. Finally, highlighting how the proposed tool of intersectionality can both sustain and even increase the legitimacy within the agencies' extant remits and within wider Swedish society as embodying widely held values. This would prevent civil servants from feeling that such action entails entering a 'danger zone' of illegitimate action. In future, we will seek to do this by designing educational materials and methods to illustrate that bringing a wider view of social justice into agency climate work is evolutionary and revelatory rather than revolutionary, with societal legitimacy.

\section{Acknowledgements}

We are most grateful to all respondents who participated in this study.

\section{Note}

1 The authors are involved in a four-year research project titled Intersectionality and Climate Policy Making: Ways Forward to a Socially Inclusive and Sustainable Welfare State. The project, financed by the Swedish Research Council for Sustainable Development, explores how climate policy-makers in government agencies work with social inclusion and how intersectional aspects relate to climate policy-making at the municipal level.

\section{References}

Ahmadi, F., Palm, I. and Ahmadi, N. (2016) Mångfaldsbarometern 2016. Gävle: Gävle University Press.

Alston, M. and Whittenbury, K. (2013) 'Does climatic crisis in Australia's food bowl create a basis for change in agricultural gender relations?, Agriculture and Human Values, 30(1), pp. 115-128.

Applbaum, A.I. (1992) 'Democratic legitimacy and official discretions', Philosophy and Public Affairs, 21(3), pp. 240-274.

Arora-Jonsson, S. and Sijapati, B.B. (2018) 'Disciplining gender in environmental organizations: the texts and practices of gender mainstreaming', Gender Work and Organizations, 25(3), pp. 309-325. 
Beetham, D. (2013) The Legitimation of Power. New York: Palgrave Macmillan.

Bellone, C.J. and Goerl, G.F. (1992) 'Reconciling public entrepreneurship and democracy', Public Administration Review, 52(2), pp. 130-134.

Bryman, A. (2004) Social Research Methods. Oxford: Oxford University Press.

Douglas, M. (1987) How Institutions Think. London: Routledge and Kegan Paul.

Dryzek, J.S. (2013) The Politics of the Earth. Oxford: Oxford University Press.

Eckersley, R. (2020) 'Greening states and societies: from transitions to great transformations', Environmental Politics. Online 10.1080/09644016.2020.1810890.

Giddens, A. (1984) The Constitution of Society. Cambridge: Polity Press.

Goffman, E. (1961) Asylums. Essays on the Social Situation of Mental Patients and Other Inmates. Harmondsworth: Penguin Books.

Goodsell, C.T. (2006) 'A new vision for public administration', Public Administration Review, 66(4), pp. 623-635.

Hatch, M.J. (1993) 'The dynamics of organizational culture', Academy of Management Review, 18(4), pp. 657-93.

Hatch, M.J. (2018) Organization Theory. Modern, Symbolic and Postmodern Perspectives. 4th Edition. Oxford: Oxford University Press.

Hysing, E. and Lundberg, E. (2016) 'Making governance networks more democratic: lessons from the Swedish governmental commissions', Critical Policy Studies, 10(1), pp. 21-38.

Hysing, E. and Olsson, J. (2018) Green Inside Activism for Sustainable Development: Political Agency and Institutional Change. Cham: Palgrave Macmillan.

Irvin, R.A. and Stansbury, J. (2004) 'Citizen participation in decision making: is it worth the effort?', Public Administration Review, 64(1), pp. 55-65.

Kaijser, A. \& Kronsell, A. (2014) Climate change through the lens of intersectionality. Environmental Politics 23(3): 417-433.

Koppell, J.G.S. (2005) 'Pathologies of accountability: ICANN and the challenge of "multiple accountabilities disorder", Public Administration Review, 65(1), pp. 94-108.

Laestadius, S. (2018) Klimatet och omställningen. Stockholm: Borea.

Lowi, T.J. (1993) 'Legitimizing public administration: a disturbed dissent', Public Administration Review, 53(3), pp. 261-264.

Lundqvist, L. J. (2004) Sweden and ecological governance. Straddling the fence. Manchester: Manchester University Press

Mackay, F., Kenny, M. \& Chappel, L.. 2010. New Institutionalism Through a Gender Lens. Towards a Feminist Institutionalism? International Political Science Review 31(5): 573-588.

Magnusdottir, G.L. and Kronsell, A. (2015) 'The (in)visibility of gender in Scandinavian climate policy-making', International Feminist Journal of Politics, 17(2), pp. 308-326.

Magnusdottir, G.L. and Kronsell, A. (2016) 'The double democratic deficit in climate policy-making by the EU commission', Femina Politica, 25(2), pp. 264-277.

Mahoney, J. and Thelen, K. (eds.) (2009) Explaining Institutional Change: Ambiguity, Agency, and Power. Cambridge. Cambridge University Press.

March, J. and Olsen, J. (1996) 'Institutional Perspectives on Political Institutions', Governance, 9(3), pp. 247-264.

Nagel, J. (2012) 'Intersecting identities and global climate change', Identities 19(4), pp. 467-476.

Naturvårdsverket (2012) Underlag till en färdplan för ett Sverige utan klimatutsläpp 2050. Stockholm: Naturvårdsverket.

Olsen, J.P. (2006) 'Maybe it is time to rediscover bureaucracy', Journal of Public Administration Research and Theory, 16(1), pp. 1-24. 


\section{Singleton and Magnusdottir}

Olsson, J. and Hysing, E. (2012) 'Theorizing inside activism: understanding policymaking and policy change from below', Planning Theory $\mathcal{E}$ Practice, 13(2), pp. 257-73.

Oscarsson, B. (2020) Organisation [online]. Available at: https://www.naturvardsverket.s e/Om-Naturvardsverket/Organisation/ (Accessed 1 October 2020).

Persson, T., Fogelström, E., Lundell, Y., Notter, M., Hansen, K., Jacobsen, K., Skovdal, A. and Dahlgren Axelsson, S. (2019) Handlingsplan för Naturvårdsverkets arbete med klimatanpassning. Stockholm: Naturvårdsverket.

Resurrección, B.P. (2013) 'Persistent women and environment linkages in climate change and sustainable development agendas', Women's Studies International Forum, 40, pp. 4033-43.

Singleton, B.E., Rask, N., Magnusdottir, G.L. and Kronsell, A. (Submitted) 'Intersectionality and climate policy making: the inclusion of social difference by three Swedish government agencies', Environment and Planning C: Politics and Space.

Stout, M. (2013) Logics of Legitimacy: Three Traditions of Public Administration Praxis. Boca Raton: CRC Press.

Svara, J.H. (2001) 'The myth of the dichotomy: complementarity of politics and administration in the past and future of public administration', Public Administration Review, 61(2), pp. 176-183.

Svara, J.H. (2006) 'Introduction: politicians and administrators in the political process - a review of themes and issues in the literature', International Journal of Public Administration, 29(12), pp. 953-976.

Swedish Government (2017) Ett klimatpolitiskt ramverk för Sverige (A Climate Policy Framework for Sweden). Bill 2016/17:146, approved by the Swedish Parliament, 15 June 2017 (Stockholm: Ministry of Environment and Energy, 14 March 2017).

Thompson, M. (2008) Organising and Disorganising. Axminster: Triarchy Press Limited.

Trafikverket. (2019) Trafikverket [online]. Available at: https://www.trafikverket.se/en/ startpage/about-us/Trafikverket/ (Accessed 1 October 2020). 